\title{
Loss Analysis and Concept Comparison for Electrically Driven Hydraulic Loader Crane
}

\author{
Amy Rankka ${ }^{1,2}$ and Alessandro Dell' Amico ${ }^{1}$ \\ ${ }^{1}$ Division of Fluid and Mechatronic Systems,Linköping University, Linköping, Sweden \\ ${ }^{2}$ Control Systems, Hiab AB, Hudiksvall, Sweden \\ E-mail: amy.rankka@liu.se,allessandro.dellamico@liu.se
}

\begin{abstract}
The load-sensing system has for a long time been the most energy efficient hydraulic system widely used for mobile machines. When replacing the combustion engine drive with an electric drive with a battery as energy source an incentive for using more energy efficient systems arise. Some promising examples of more energy efficient systems are independent metering systems, pump controlled systems and open flow control systems. Before getting to deeply involved in a specific design, an investigation of the intended application is of importance. The objective of this study is to present a large number of energy efficient designs for the hydraulic system of an electrified loader crane by the means of a loss analysis and a high level concept comparison. To be able to cover a large design space all systems are modeled based on static pressure-flow relations for their components.

Based on measurements, the losses from simultaneous operation, backpressure losses and load holding valve losses are found to be the largest loss contributors in the hydraulic system. If an electrical supply system is added to the reference load sensing system, the overall efficiency is found to be $23 \%$. The hydraulic system it is found to account for $62 \%$ of the losses and the drive system for $38 \%$.

The concept comparison shows that a two or four pump system with recuperation possibilities can decrease the energy consumption of the complete system on the studied working pattern by about $50 \%$.
\end{abstract}

Keywords: loss analysis, energy study,concept development, electrified mobile hydraulics

\section{Introduction}

Conventional mobile hydraulic systems are known to suffer from large losses [1] and with the ongoing electrification the losses become more evident as they directly affect the size of the heavy and costly battery. The load sensing system, which will be used as reference in this study, is the most energy efficient system widely used but still suffers from losses due to e.g. different pressure levels of active hydraulic functions. There are different ideas on how to decrease the losses, see e.g. [2], [3], [4] and [5], but this study investigates which ideas are best suited for the reference application. A loss analysis is performed on the reference system to sort out the largest loss contributors. An energy analysis on different concept systems based on real life working patterns is then performed to find the design changes that have the greatest impact on the power consumption. Static energy calculations are used to cover a large number of systems.

All concepts in this study will be driven by electrical motors. The control possibilities of the electrical motor open up for a number of concepts that are not motivated when a combustion engine is considered as the power source.

The reference system for this study is the hydraulic system of a loader crane with four hydraulic functions; slew, 1 st boom, 2nd boom and extension. The slew function is driven by a symmetric cylinder and the other functions by asymmetric cylinders. A figure of the crane with placing of the cylinders is displayed in fig. 1 and a simplified view of the hydraulic system can be found in fig. 2. The hydraulic system consists of a pressure compensated directional valve and pilot operated load holding valves connected to each cylinder for safety. The cylinder design will not be investigated in this study and will consequently be left out of the analysis. The pump together with an electric motor will be included in the analysis to show the relation between drive system and hydraulic system 
losses and to allow systems with different number of pumps and different capabilities of recuperation of energy to be compared. In order to make the new concepts commercially interesting, the study aims at presenting concept systems that reduce the energy consumption as much as possible with as little changes to the reference system as possible.

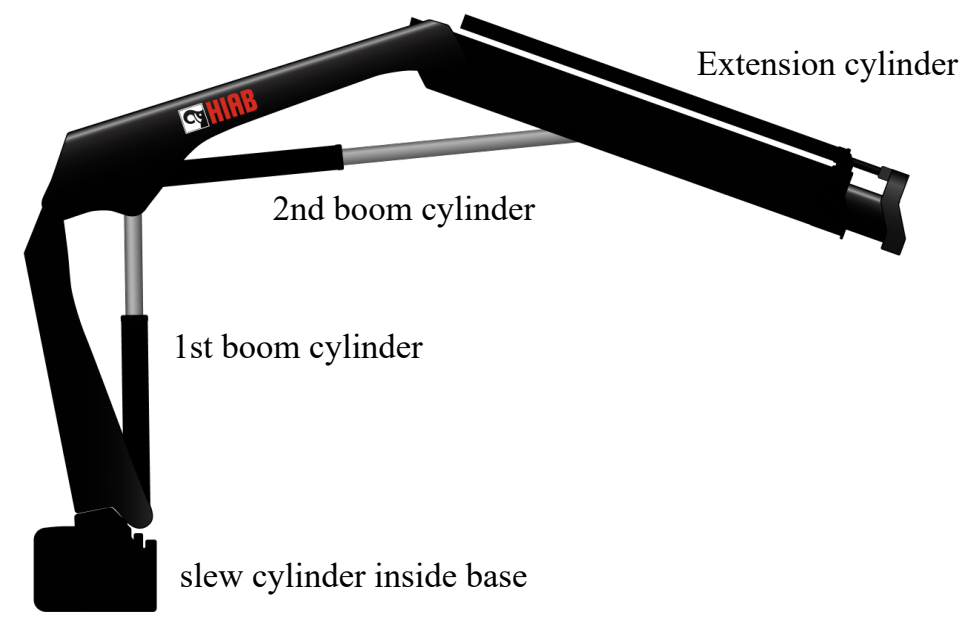

Figure 1: Reference system crane with placement of four hydraulic cylinders.

\section{Method}

Loss analyses are good foundations to design new systems on and done on hydraulic machines e.g. by [5], [6] and [7]. Some of the same ideas are applied to a loader crane in this study and load holding valves and components of the electric drive are added to the analysis. This work aims at investigating a much larger design space of new systems than what has been done in the above mentioned studies. The aim is not to propose one solution over another but to provide the basis for deciding which systems to investigate further. In order to minimize the time spent on each system before a first selection can be done, a method of modeling static pressure-flow relations for each component in the hydraulic system that can be used both to build the reference system and new systems is used. Dynamic properties of different systems will thus not be considered. The method can be summarized by the following steps:

- Step 1: Data gathering of reference system to get data for modeling and energy analyses.

- Step 2: Modeling of components in reference system.

- Step 3: Loss analysis of reference system. Hydro-mechanical and volymetric losses are considered for the pump but only pressure drop losses will be considered in the rest of the hydraulic system. Flow losses are mainly the flows required for valve actuation and the load sensing control but left out of the analysis. No frictional losses in the cylinders are included.

- Step 4: Concept screening.

- Step 5: Modeling of components for new concept systems.

- Step 6: Energy analysis of new concept systems. As in the loss analysis, only pressure drop losses will be considered and power consumption for valve actuation and sensors will thus not be compared for different systems.

\section{Measurements and Reference System Mathematical Modeling}

A model of the reference system based on pressure drop models for different components is needed for the loss analysis. The component models are also needed for the energy analysis of new concept systems where some parts of the reference system will be kept. All components in fig. 2 with arrows indicating the loss energy flow are modeled and described more thoroughly in sec. 3.1 to 3.5 .

The input to the analysis will be demanded cylinder pressures and flows and to get relevant data measurements of cylinder pressures and spool positions of a crane in the field have been done during several months. The spool 
positions can be used to estimate flow since the directional spools are pressure compensated. A more detailed description of this data gathering and a representative drive cycle can be found in [8]. Since the calculations in this study are static the complete data set is used rather than the drive cycle for a greater variation in crane movements.

To establish the static relations between flow and pressure drops for the model of the reference system measurement on a laboratory crane have been done. For these measurements, each function was equipped with pressure sensors according to fig. 2 as well as spool position sensors. Each cylinder was operated at different static working points and the pressure drops over the components connected to the cylinder were measured.

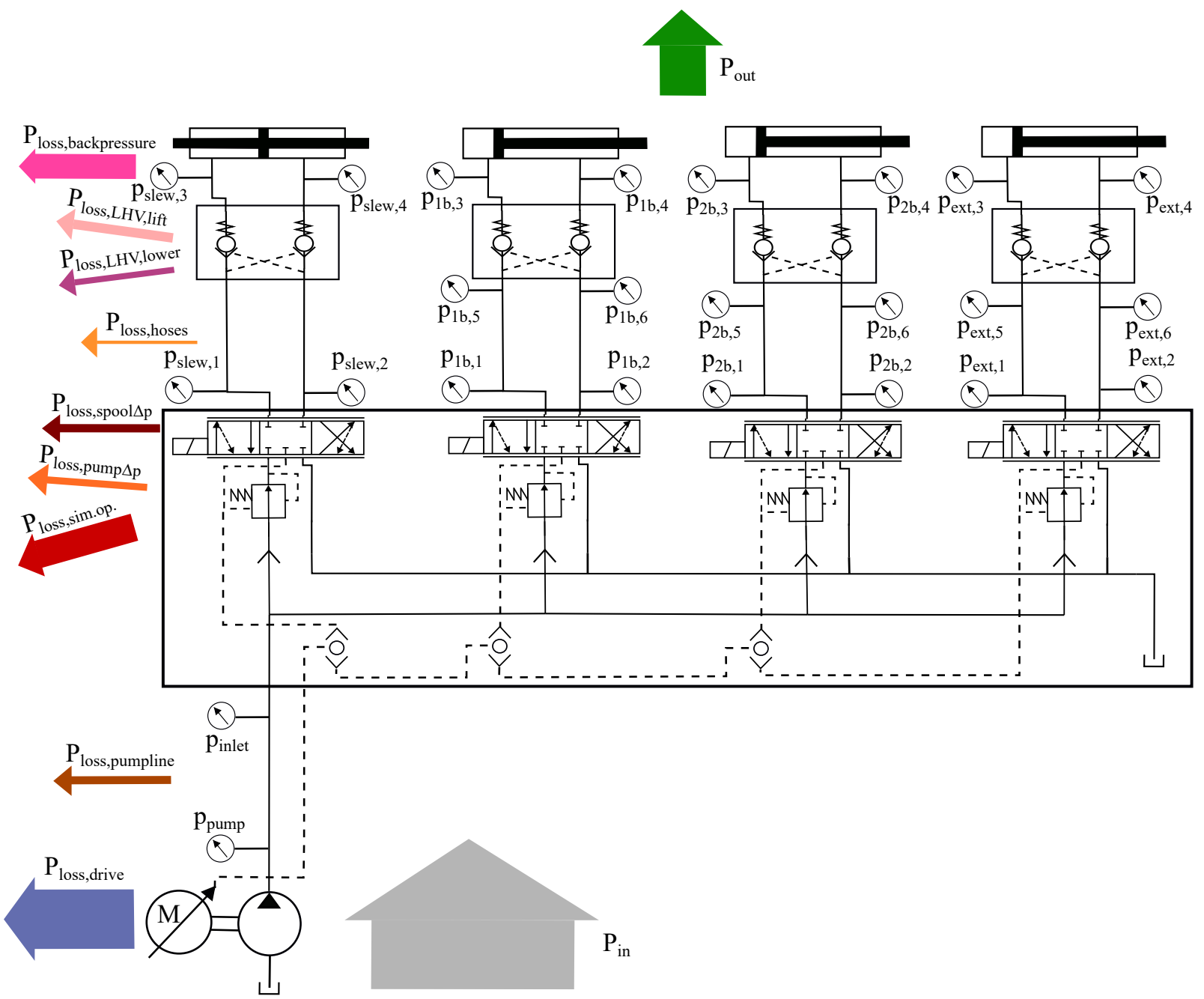

Figure 2: Reference system with loss indicators for each component and placement of pressure sensors.

\subsection{Mathematical Models and Definitions of Losses from Pumpline and Main Valve}

For the load-sensing reference system the pump pressure margin is controlled to a constant value. This margin is set to overcome the losses in the hoses and filters in the pumpline as well as the pressure drop over the directional valve. The pressure drop over the spools in the directional valve is kept constant by pressure compensators but the pressure drop in the pumpline is flow dependent.

For the reference system the pump pressure margin is assumed to be 28 bar which is the recommended lowest value by the manufacturer. The actual pressure drop in the pumpline as a function of the flow is estimated using measurement data of sensors of $p_{\text {pump }}$ and $p_{\text {inlet }}$ according to fig. 2 . The actual pressure drop is set as one loss component according to eq. 1 and the additional pressure that has to be built up due to the fixed pressure margin as one component according to eq. 2. The pressure drop over the directional spools is assumed to be 8 bar when the compensator is within its working range and this loss component is described by eq. 3 .

$$
P_{\text {loss }, \text { pumpline }}=f_{\text {pumpline }}\left(q_{\text {pump }}\right) q_{\text {pump }}
$$




$$
\begin{gathered}
P_{\text {loss }, \text { pump } \Delta p}=\left(\Delta p_{\text {pump }}-\Delta p_{\text {spool }}-f_{\text {pumpline }}\left(q_{\text {pump }}\right)\right) q_{\text {pump }} \\
P_{\text {loss }, \text { spool } \Delta p}=\Delta p_{\text {spool }} \cdot q_{\text {pump }}
\end{gathered}
$$

The relation between the actual pressure drop in the pumpline, $f_{\text {pumpline }}\left(q_{\text {pump }}\right)$, and the constant pressure margins for different flow levels is displayed in fig. 3 .

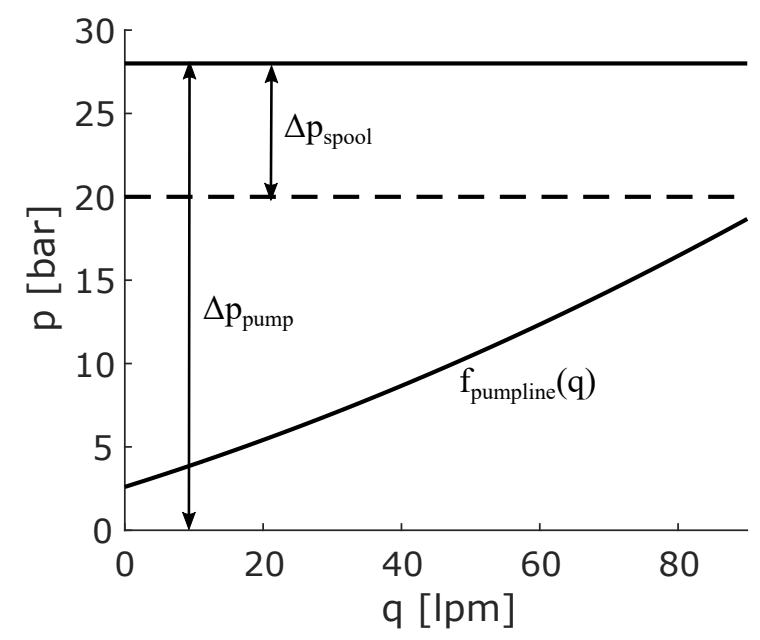

Figure 3: Actual pressure drop in pumpline and constant pressure margins for pump and spool. For high flows the actual pressure drop in the pumpline plus the spool pressure margin almost matches the pump pressure margin but for low flows the losses are much higher than needed. $f_{\text {pumpline }}(q)$ is estimated using measurement data.

\subsection{Definition of Losses from Simultaneous Operation}

Since all functions share the same pressure source losses occur when two or more functions with different pressure levels are active. These losses are defined according to eq. 4 where $i$ denotes slew, 1 st boom, 2nd boom or extension and $p_{i, 1}$ and $p_{i, 2}$ are defined according to fig. 2.

$$
\begin{aligned}
& P_{\text {loss }, \text { sim.op. }}=\sum_{i=1}^{4}\left(p_{l s}-p_{i, v}\right) q_{i} \\
& \text { where } \\
& p_{i, v}=\max \left(p_{i, 1}, p_{i, 2}\right) \\
& p_{l s}=\max \left(p_{1, v}, \ldots, p_{4, v}\right)
\end{aligned}
$$

\subsection{Mathematical Models and Definitions of Losses from Load Holding Valves and Cylinder Hoses}

The function of the load holding valves (LHV) is to only allow motion of the cylinder when this is requested by the operator. This is, somewhat simplified, achieved by a check valve on each side of the cylinder that can be piloted open by the pressure on the opposite side. For the 1 st and 2 nd boom this pilot pressure is the only pressure required to lower the cylinders. If one of these functions is the only active function and performing a lowering motion, all the pressure that has to be built up by the pump is defined as a loss. During lifting motions the check valves give rise to a pressure drop that is determined by the pressure required to open the valve and the flow passing through the restriction. Models for this relation are produced for each of the four functions and can be found in fig. 4 together with models for the pressure drops in the hoses between the main valve and the load holding valves. Note that no losses are assumed in the hoses between the main valve and load holding valves for the slew function since the valves are closely connected in the crane base.

The losses from the load holding valves are divided in losses during lifting, $P_{\text {loss }, L H V, \text { lift }}$, and losses during lowering of 1 st and 2nd boom, $P_{\text {loss }, L H V, l o w e r}$, according to eq.5 and 6. The losses from the hoses, $P_{\text {loss, hoses, }}$, are defined accoding to eq. 7. $i=1$ denotes slew, $i=21$ st boom, $i=32$ nd boom and $i=4$ extension. 

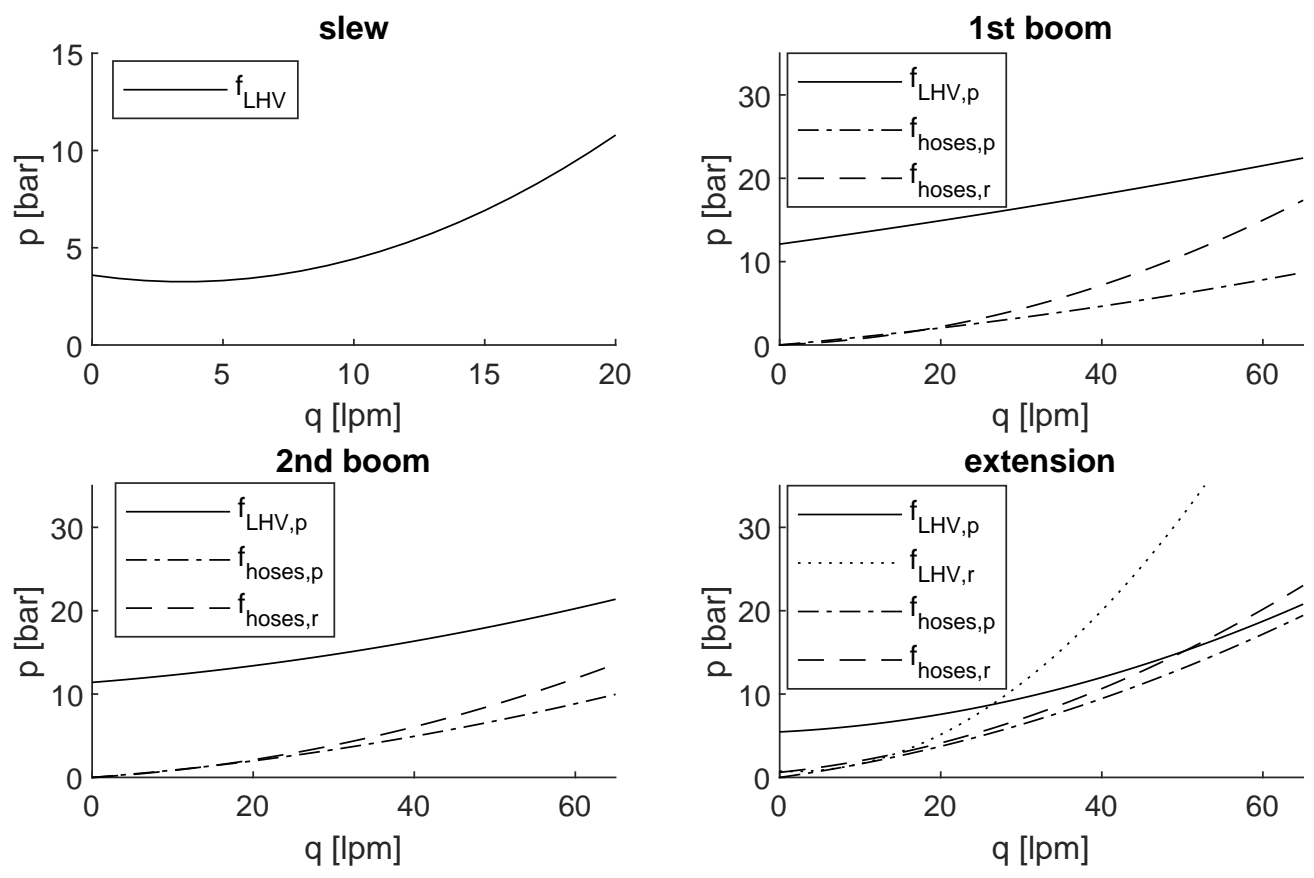

Figure 4: Models for flow-dependent pressure drop in LHV and hoses for each of the four functions. $p$ denotes piston side and r rod side. Note that the LHV is symmetrical for the slew and that the pressure drop over the LHV on the rod side is constant for 1 st and 2nd boom due to gravitation aided lowering and thus not displayed here.

$$
\begin{aligned}
& P_{\text {loss }, L H V, l i f t}=\sum_{i=1}^{4} f_{L H V, i}\left(q_{i}\right) q_{i} \\
& \text { where }
\end{aligned}
$$

$f_{L H V}$ is from piston or rod side depending on cylinder movement direction

$$
\begin{gathered}
P_{\text {loss }, \text { LHV }, \text { lower }}=\sum_{i=2}^{3} p_{\text {i,loss }} q_{i} \\
\text { where } \\
p_{i, \text { loss }}=p_{\text {pump }}, \text { if } i \text { is the only active function } \\
p_{i, \text { loss }}=p_{i, 2}, \text { otherwise } \\
P_{\text {loss }, \text { hoses }}=\sum_{i=2}^{4} f_{\text {hoses }, i}\left(q_{i}\right) q_{i} \\
\text { where } \\
f_{\text {hoses }} \text { is from piston or rod side depending on cylinder movement direction }
\end{gathered}
$$

\subsection{Definition of Losses from Backpressure}

When performing a lifting motion with a cylinder the pressure in the opposite cylinder chamber would ideally be equal to the tank pressure. The different valves and restrictors between the cylinder and the tank together with an incorrect matching of in and out flow of the cylinder result however in that the pressure can be quite high. The additional pressure in the active cylinder chamber that has to be built up to overcome this backpressure is defined, multiplied with the input flow, as the backpressure losses, $P_{\text {loss,backpressure }}$, see eq. 8 where $A_{\text {active }}$ and $A_{\text {back }}$ are the cylinder areas on the active and back side respectively and $p_{i, 3}$ and $p_{i, 4}$ are defined according to fig. 2. $i$ denotes slew, 1st boom, 2nd boom or extension 


$$
\begin{gathered}
P_{\text {loss }, \text { backpressure }}=\sum_{i=1}^{4}\left(p_{i, \text { back }} \frac{A_{\text {active }}}{A_{\text {back }}}-p_{\text {tank }}\right) q_{i} \\
\text { where } \\
p_{i, \text { back }} \in\left[p_{i, 3}, p_{i, 4}\right]
\end{gathered}
$$

\subsection{Drive System Mathematical Models}

The models for pump and motor used both for the reference system and new concept systems are based on the, by the manufacturers supplied, efficiency maps in fig. 5. The torque axis of the motor maps is scaled based the maximum torque required for different systems. To maximize the efficiency of the pump and motor the size of the motor is chosen so that $60 \%$ of the maximum torque is the torque required to get maximum pressure at $2000 \mathrm{rpm}$. Fixed pumps are assumed and the displacement is set so that maximum flow is achieved at $2000 \mathrm{rpm}$. In cases the electric motor is operated as a generator or the pump as a hydraulic motor the same efficiency maps are used. The model for the efficiency of the inverter is displayed in fig. 6 and based on data for a typical inverter [9].The power rating of the inverter is set to correspond to the maximum power rating of the motor.
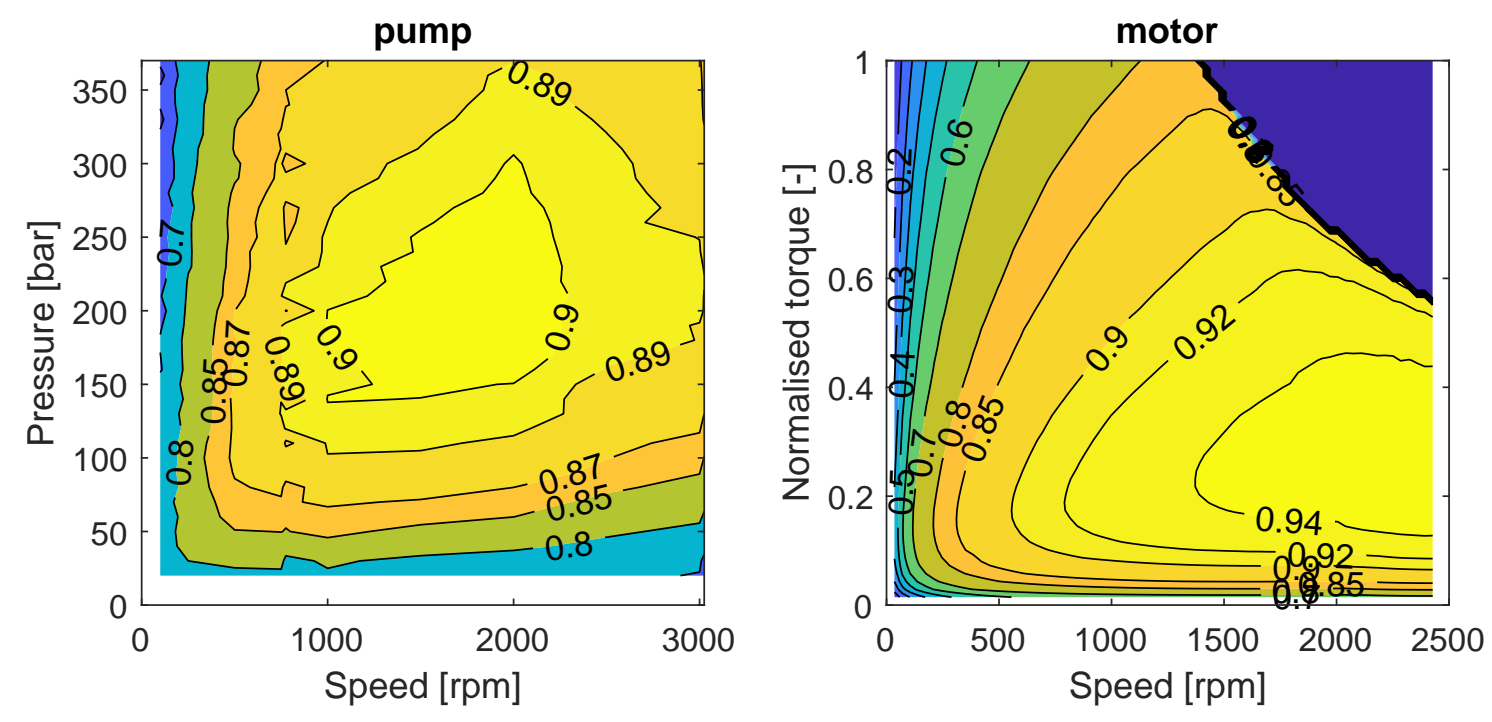

Figure 5: Efficiency maps of pump and electric motor used for reference model and new concept models.

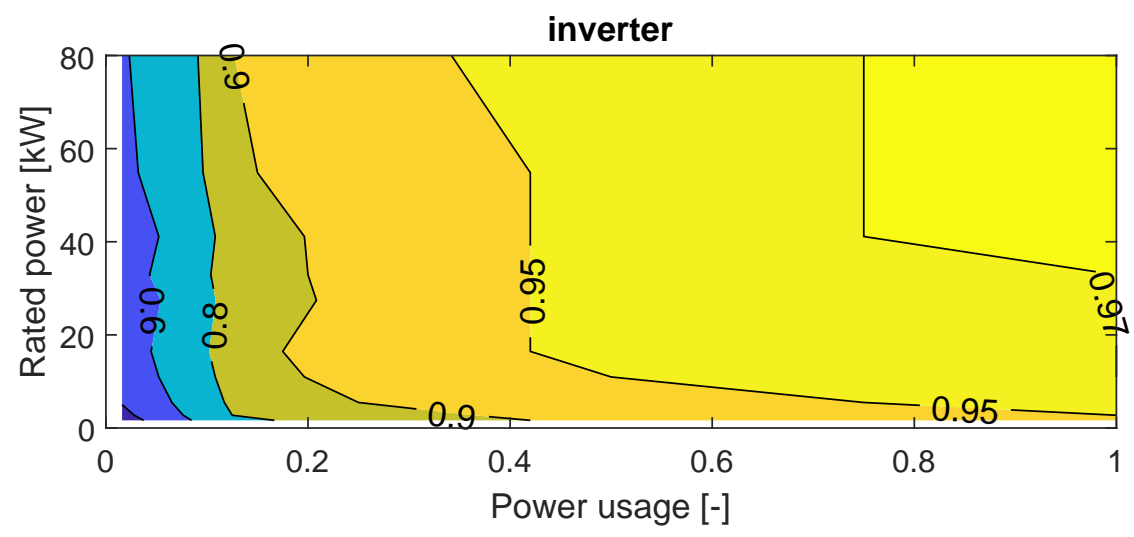

Figure 6: Efficiency map of inverter used for reference model and new concept models. 


\section{Reference System Energy Loss Analysis}

In order to get a deeper knowledge of where the large energy losses in the system are a loss analysis is made based on the model of the reference system. Calculations are done using the models from sec. 3 and the input is the cylinder pressures and flows from the measurements of the field crane described in sec. 3 . The required power at different points in the system is calculated and the resulting distribution between losses in the drive system $\left(P_{\text {loss,drive }}\right)$, losses in the hydraulic system $\left(P_{\text {loss,hyd }}\right)$ and useful cylinder power $\left(P_{\text {out }}\right)$ is presented in fig. 7 a. To get an indication of the size and usage of the application the distribution of the calculated pump states are displayed in fig. 8. The pump power is equal to the sum of the hydraulic system losses and the cylinder power. The concept analysis will be focused only on improving the hydraulic system and the distribution of losses on its different components is presented in fig. $7 \mathrm{~b}$.

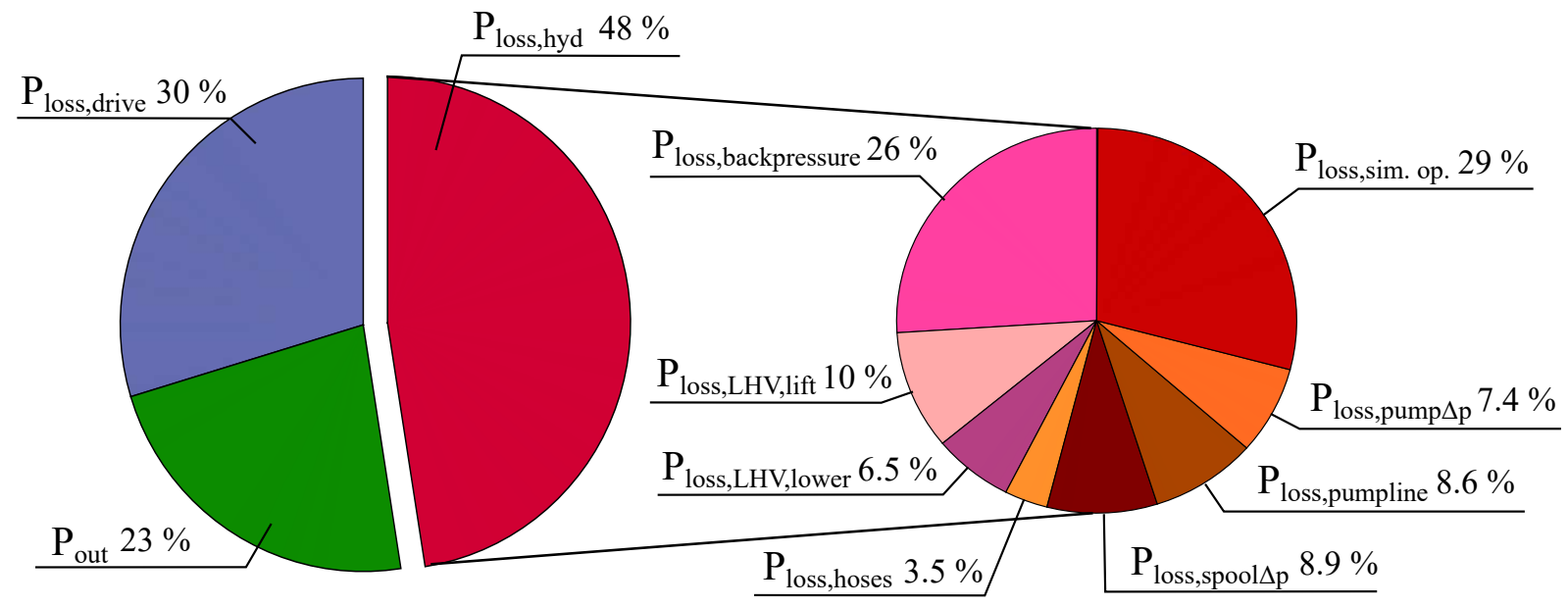

(a)

(b)

Figure 7: Distribution of power on drive system losses, hydraulic system losses and output power (a) and distribution of losses in hydraulic system (b). The denominations are taken from fig. 2.
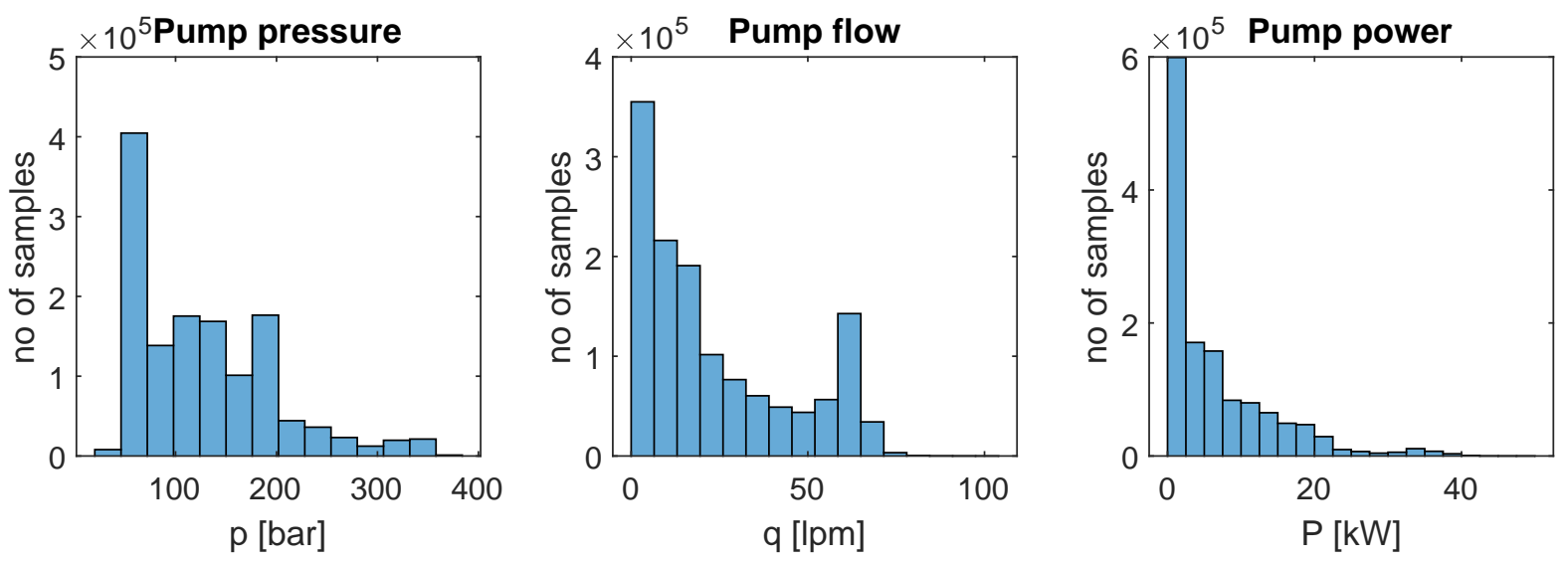

Figure 8: Distribution of pump pressure, pump flow and pump power calculated from input cylinder data and reference system model.

\section{Concept Screening and Concept Mathematical Models}

The energy efficiency of the hydraulic system can be improved by reducing the losses described in previous sections or make use of lowering energy. Different basic concepts are presented in tab. 1 together with what losses they can reduce. The concepts are described in sec. 5.1 to 5.5. Additionally, the concept of recuperating energy is described in sec 5.6. It can be noted that none of the concepts reduce the losses in the hoses on the crane or the pumpline. The 
hoses on the armsystem can only be removed if the power pack is mounted directly onto the cylinders, a concept known as electro-hydraulic actuator. This solution is not investigated since is not considered to be plausible to mount large motors and pumps on the armsystem. The increase in energy consumption from lifting the additional weight, which can be quite significant [10], is considered to be higher than the decrease from removing the hoses. The losses in the pumpline could be reduced by a shorter line, different filter design etc., but will not be discussed further in this study.

Table 1: Loss reduction capabilities of basic concepts.

\begin{tabular}{cccccc}
\hline Concept & $P_{\text {loss }, \text { sim-op }}$ & $P_{\text {loss, }, \text { pump } \Delta p}$ & $P_{\text {loss,spool } \Delta p}$ & $P_{\text {loss }, \text { LHV }}$ & $P_{\text {loss,backpressure }}$ \\
\hline Electric load holding valves & & & & $\mathrm{x}$ & $(\mathrm{x})$ \\
Flow control & & $\mathrm{x}$ & & \\
Open flow control & & $\mathrm{x}$ & $\mathrm{x}$ & & $\mathrm{x}$ \\
Independent metering & $\mathrm{x}$ & & & \\
Multiple pumps & $\mathrm{x}$ & & & \\
\hline
\end{tabular}

The basic concepts can be seen as means that solve different requirements in the system design and that can be combined into a complete system setup according to the function-means tree in fig. 9.

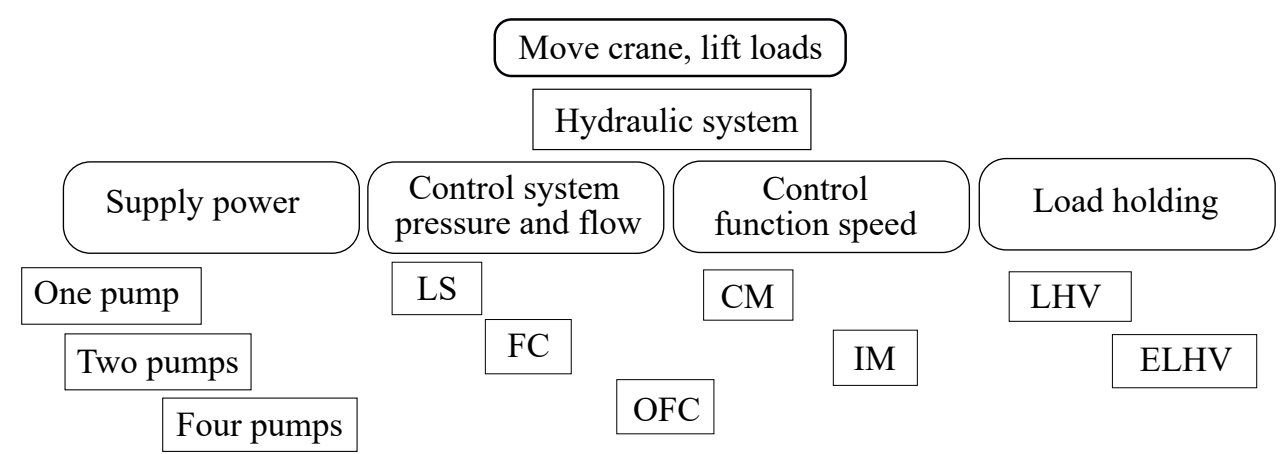

Figure 9: Function-means tree describing the four main functions of the hydraulic system of the crane and different means that can solve the functions. Every system design needs to be compiled by one of the means for each function.

The calculations of the energy consumption of the concepts is done using a combination of the models from the reference system and models of new components described in sec. 5.1 to 5.6. Since static calculations are used, the input data can be the same working point data from the long-term log of operation from the field crane as in the loss analysis.

\subsection{Electrically Controlled Load Holding Valves (ELHV) Mathematical Model}

The pilot pressure controlled load holding valves could be replaced with electrically controlled valves. There are not yet any electrically controlled valves on the market designed specifically for load holding of mobile machines. On-off valves are assumed in the calculations in this study but proportional poppet valves could also be considered. These valves can be selected to have a quite low pressure drop across them when they are fully open, both on the active and on the back side, and no pilot pressure will have to be built up by the pump to perform a lowering motion. Characteristics of an on-off valve according to fig. 10 is used to calculate the pressure drop during lifting motions and on the backside of the cylinder for systems with ELHV. Ideal switching of the valve is assumed in the calculations but in a real system pressure equalizing before opening the valve might be needed [11] to prevent a drop of the load when starting a lowering motion. 

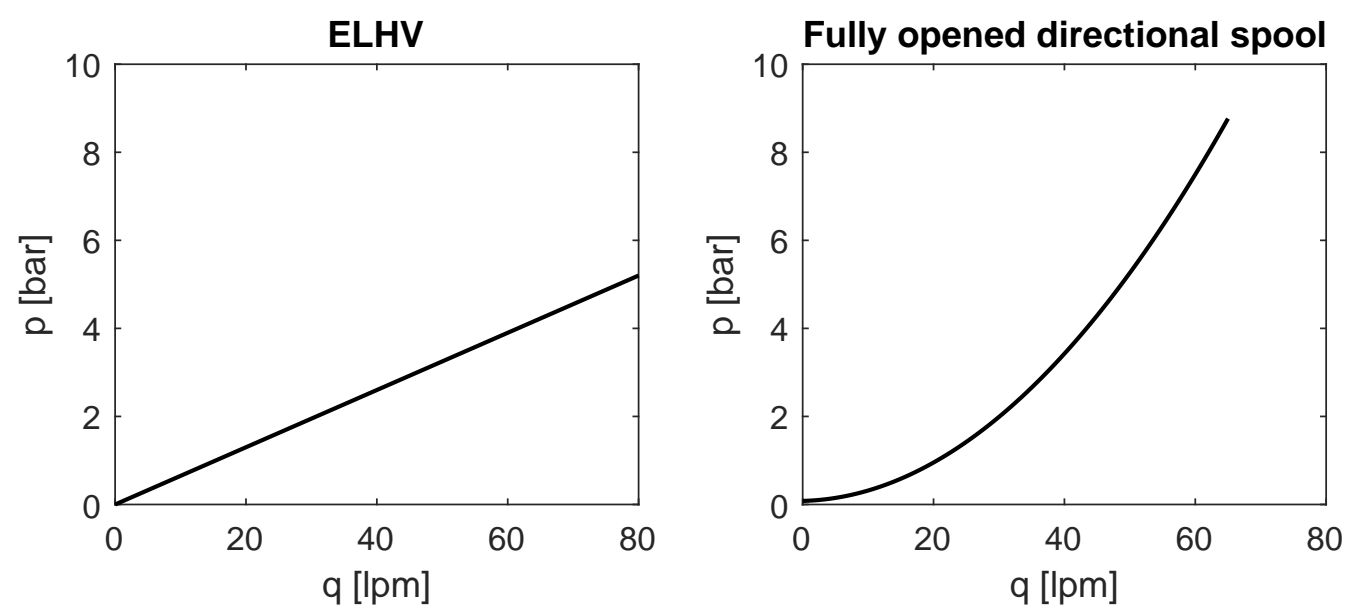

Figure 10: Models of pressure drop for on-off valves used as ELHV (left) and fully open directional spool during OFC (right). Models are taken from supplier data.

\subsection{Flow Control (FC) Mathematical Model}

With an electric drive, speed control is easy to implement and the flow demand of the system can be calculated from the operator commands and fed forward to the controller that calculates the required motor speed. The control aim is to keep the required velocity instead of keeping a constant pump pressure margin and the pump pressure will not be higher than needed to overcome the losses in the pumpline according to eq. 1 and to keep the pressure drop over the valve. The pressure drop over the valve is assumed to be $\Delta p_{\text {spool }}$ plus an additional 2 bars over the inlet section and compensator valve.

A small overestimation of the flow demand might be needed to make up for the electrical motor being slower than a variable pump to alter the flow. The delivered flow could also be too high due to model errors and some modification is needed for a valve designed for load sensing with conventional pressure compensators to avoid high losses in these cases. Flow sharing compensators can be used [12], or a shunt valve that senses the highest load pressure. Another possibility is to introduce more sensors to the system and either measure the position of the conventional compensators and lower the flow if none of the compensators is close to fully opened [13] or measure and compare the inlet pressure to the highest load pressure. However, the calculations in this study assume a perfect match of the delivered flow.

Flow control software under the name of Flow on Demand is offered by Bucher [14] and the concept is marketed by Bosch by the name Electrohydraulic Flow Matching [15].

With a pump with electronically controlled displacement flow control can also be achieved with a fixed speed prime mover. Such a system with a comubstion engine has been developed [16] and the system solution is offered by Weiss Mobiltechnik GmbH [17].

\subsection{Open Flow Control (OFC) Mathematical Model}

In addition to flow control of the total pump flow the flow to the heaviest load can be controlled directly by the pump flow after lighter functions have taken their required flow controlled be the directional spools. The directional spool for the heaviest function is kept fully open and thus the pressure drop over the valve is minimized instead of controlled to a constant value. The pressure drop in that case is calculated using the characteristics of an off-on valve according to fig. 10 since measurement of the spool on the reference crane was not possible. The spool is assumed to be opened fully by an electric command as soon as a function becomes the heaviest one. In a real system the spool might have to be ramped from partially closed to fully open [18] to avoid oscillations.

Open flow control could also be partially realized hydraulically with a three-way pressure compensator at the valve inlet [19]. 


\subsection{Independent Metering (IM) Mathematical Models}

As opposed to the conventional coupled metering (CM) independent metering system have independently controlled spools for meter in and meter out of the cylinders. This type of system offers several possibilities of energy consumption reduction and is further divided into three categories:

- IM 1: The backpressure in the cylinder can be controlled to be as low as possible. If combined with electric load holding valves, it is assumed that the backpressure can be minimized to the pressure to overcome the losses in the load holding valve, a fully opened directional spool and the hoses between these two valves. In a real system, a higher backpressure might be needed to get acceptable dynamic properties. Especially the slew function might suffer from heavy oscillations if not sufficiently braked.

- IM 2: A regeneration circuit that transforms the pressure up and flow down can be opened for asymmetrical cylinders that are extending. This reduces the pressure difference between functions and thus lowers the losses from simultaneous operation.

- IM 3: Circuits connecting cylinders and allowing for regeneration from a lowering cylinder to a lifting could also be possible which lower the input energy needed.

Recuperation to an energy storage, further described in sec. 5.6, is facilitated since the meter out flow can be throttled or controlled by the braking electric motor to get a safe lowering motion without the meter in flow disturbing. There are many different valve architectures for independent metering systems. One example of a setup that could lower the losses from all three categories is displayed for a circuit with two functions in fig. 11 (a).

A large number of valves is needed to get full regeneration capacity. Calculations with regeneration between functions has only been made for the two-pump setups since the architecture and number of valves are considered to be too complex in relation to the time the functionality might be possible to use for a single-pump setup.

The calculations assume ideal switches between different modes of operation. Smooth switching of modes with different flow paths for a single cylinder seems to be possible to achieve [2], [20], but such control will always come with some losses. Regeneration between functions introduces more switching and after ramps or other modification to the switches have been applied there might not be so much more time left when functions are in the states where regeneration is possible.

An independent metering valve, marketed as CMA, is available at the market by Eaton [21]. 


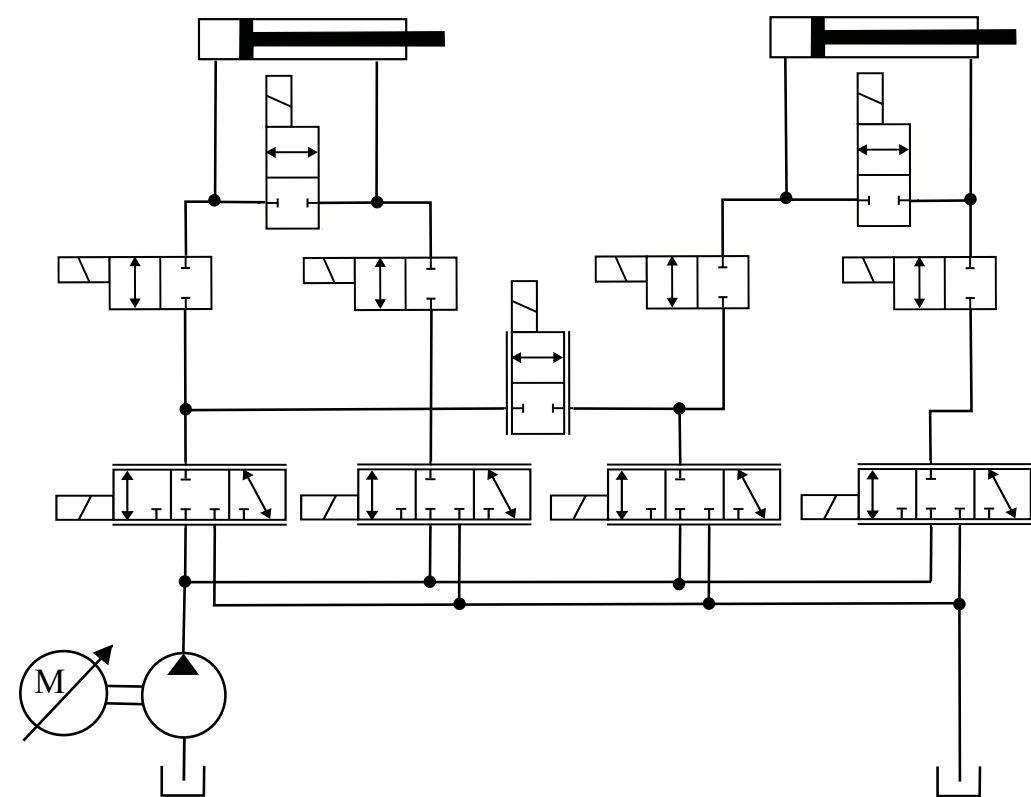

(a)

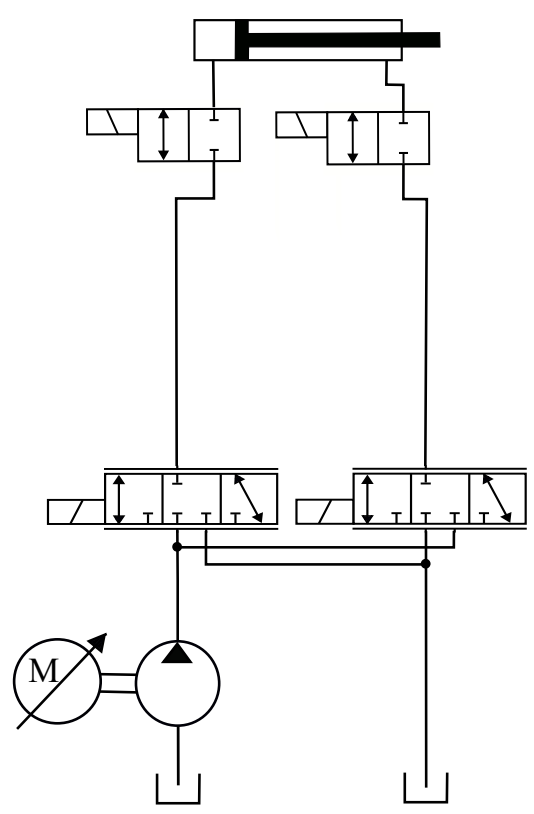

(b)

Figure 11: Examples of new system designs. (a): IM system for one of the circuits in a two pump system with ELHV and possibility to regenerate both on cylinders and between functions and recuperate energy back to the battery. (b): Open circuit for one of the circuits in a four pump system. ELHV and IM are selected for this configuration

\subsection{Multiple Pump Systems}

Using a system with more than one pump reduces the losses from simultaneous operation and reduces the number of mode switches required for open flow control, regeneration between functions and recuperation. A four and a two pump system are investigated. The two-pump system uses the most energy efficient fixed configuration calculated on a system with LS-CM-LHV, the slew and 1st boom connected to one pump and the 2nd boom and extension connected to the other. In a four pump system, the flow to each function can be controlled directly from its pump. In order to stay as close to the reference system as possible open circuits are assumed which means that directional valves are required to direct the flow from the pump and tank, see fig. 11 (b). Ideal swithing of different modes of operation is assumed in the calculations but in a real system, it should be considered that the rotational direction of the pump in an open circuit will be dependent both on force and velocity direction of the cylinder which can cause speed interruptions when a load goes over center [22].

\subsection{Recuperation to Energy Storage}

An electric drive offers the possibility of recuperating energy back to the battery. Since this does not require any additional components this alternative will be investigated rather than one using another energy storage. In a system with one pump per function the recuperation can be fully exploited. If functions are sharing a pump, recuperation is only possible when no function is requiring power from the battery. It is only assumed that recuperation is possible from the 1 st and 2 nd boom during lowering motions. 


\section{Energy Analysis}

Different system setups are created by combining one mean for each function according to fig. 9 and recuperation possibilities are added to some systems. The new basic concepts are combined to clearly show the reduction in energy consumption when moving from the reference system to more complex systems. The reduction is shown both for the hydraulic system and for the hydraulic and drive system combined. Calculations are done using combinations of the models from sec. 3 and 5 . The cylinder power demand from the field measurements is used as input and the results for 30 different systems are presented in tab .2.

Table 2: Energy consumption reduction for the hydraulic system (energy from pump) and for the complete system (energy from battery) with regards to the reference system for different system setups.

\begin{tabular}{lllllll}
\hline Supply power & $\begin{array}{l}\text { Control system } \\
\text { pressure }\end{array}$ & $\begin{array}{l}\text { Control func- } \\
\text { tion speed }\end{array}$ & Load holding & Recup. & $E_{\text {pump,red }}$ & $E_{\text {bat, red }}$ \\
& flow & & & & & \\
\hline 1 pump & LS & CM & LHV & - & - & - \\
1 pump & LS & IM2 & LHV & - & $4 \%$ & $3 \%$ \\
1 pump & FC & CM & LHV & - & $6 \%$ & $6 \%$ \\
1 pump & OFC & CM & LHV & - & $9 \%$ & $9 \%$ \\
1 pump & LS & CM & ELHV & - & $8 \%$ & $11 \%$ \\
1 pump & OFC & CM & ELHV & - & $17 \%$ & $18 \%$ \\
1 pump & LS & IM1 & ELHV & - & $20 \%$ & $20 \%$ \\
1 pump & LS & IM1+2 & ELHV & - & $24 \%$ & $23 \%$ \\
1 pump & FC & IM1+2 & ELHV & - & $29 \%$ & $28 \%$ \\
1 pump & OFC & IM1+2 & ELHV & - & $32 \%$ & $31 \%$ \\
2 pumps & LS & CM & LHV & - & $22 \%$ & $11 \%$ \\
2 pumps & LS & IM2 & LHV & - & $22 \%$ & $11 \%$ \\
2 pumps & FC & CM & LHV & - & $29 \%$ & $18 \%$ \\
2 pumps & OFC & CM & LHV & - & $33 \%$ & $22 \%$ \\
2 pumps & LS & CM & ELHV & - & $33 \%$ & $26 \%$ \\
2 pumps & LS & IM1 & ELHV & - & $39 \%$ & $32 \%$ \\
2 pumps & LS & IM1 +3 & ELHV & - & $44 \%$ & $39 \%$ \\
2 pumps & OFC & IM1 & ELHV & - & $48 \%$ & $41 \%$ \\
2 pumps & OFC & IM1+2 & ELHV & - & $49 \%$ & $41 \%$ \\
2 pumps & OFC & IM1+2 & ELHV & x & - & $45 \%$ \\
2 pumps & OFC & IM1+2+3 & ELHV & - & $53 \%$ & $47 \%$ \\
2 pumps & OFC & IM1+3 & ELHV & x & - & $53 \%$ \\
2 pumps & OFC & IM1+2+3 & ELHV & x & - & $54 \%$ \\
4 pumps & LS & CM & LHV & - & $26 \%$ & $10 \%$ \\
4 pumps & FC & CM & LHV & - & $34 \%$ & $19 \%$ \\
4 pumps & OFC & CM & LHV & - & $37 \%$ & $23 \%$ \\
4 pumps & LS & CM & ELHV & - & $39 \%$ & $32 \%$ \\
4 pumps & LS & IM1 & ELHV & - & $45 \%$ & $37 \%$ \\
4 pumps & OFC & IM1 & ELHV & - & $54 \%$ & $45 \%$ \\
4 pumps & OFC & IM1 & ELHV & x & - & $51 \%$ \\
\hline
\end{tabular}

\section{Discussion}

The losses from the load holding valves are found to account for $11 \%$ of the input energy to the hydraulic system, the energy analysis of new single pump systems shows that a significant part of these losses can be removed by electrically controlled valves that reduce the energy consumption of the hydraulic system by $8 \%$. A significant part of the backpressure losses (18\% of the input energy to the hydraulic system) can be reduced by combining the electrically controlled load holding valves with independent metering of the meter in and meter out spools which gives an additional reduction of 12 percentage points. Implementing flow control reduces the energy consumption by $6 \%$ but the additional reduction in going from flow control to open flow control is only 3 percentage points and open flow control is perhaps not worth the effort of implementing. To add regenerative valves on asymmetric cylinders is also quetionable since they have a very small impact on the losses from simultaneous operation and only reduce the energy consumption by $4 \%$. On a 2-pump system, there is no gain at all in adding regenerative 
valves.

The energy analysis shows that a 2-pump system could have a better energy performance than a 4-pump system even though the losses from simultaneous operation can only be completely removed by the latter. This result shows the impact of over dimensioned, with regards to mean power, components in the drive system. However, in order for the most energy efficient 2-pump system to work a complex control scheme of regeneration between functions must be implemented. The question then becomes whether to invest in developing such a complex control or whether to optimize the hardware layout of a drive system with four pumps.

It is clear that a suitable component selection and control strategy for the drive system is important, a lot of the energy gained in the hydraulic system of 2- and 4-pump systems is lost in the drive system due to poor part load efficiencies. In a real life scenario it might be even worse when the available sizes of pumps and motors are limited. One way to improve the efficiency of the drive system is to put power limits on functions and thus being able to select smaller components that will be used more in the regions of high efficiency. For some applications the power limitation might only affect a short portion of the operation time and it might be acceptable to get reduced speed for heavy loads.

In addition, weight and volume of the components will be issues for a commercial product. It is also important to keep in mind that while an electric drive to a hydraulic application on truck or other machine is an add-on today this does not have to be the case in the future when the machine itself will be electrified. The possible interfaces to the driveline will be important to consider, especially if developing a multi-pump system.

\section{Conclusions}

The loss analysis makes it clear that there are several large contributors to the energy losses in the reference system, the losses due to simultaneous operation and backpressure in the cylinders being the two largest. The load holding valves and constant pressure margins are also large loss contributors.

If only a minor reduction in energy consumption is required there are many different ways of reaching the target reduction. The energy analysis of new concept systems shows that changing to electrically controlled load holding valves has the single greatest impact on power consumption without adding any extra components. It can also be noted that it is possible to reach up to $9 \%$ reduction with one pump or $22 \%$ with two pumps while keeping the valve setup of the reference system. If the aim is to reduce the energy consumption as much as possible it can be noted that a 2-pump system can achieve about the same energy performance as a 4-pump system, $54 \%$ and $51 \%$ reduction respectively.

\section{Acknowledgment}

The authors would like to thank Hiab AB for their contribution to this paper. The work in this paper was sponsored by the Swedish Energy Agency and is part of STEALTH, Sustainable Electrified Load Handling, App. no 44427-1. 


\section{Nomenclature}

\begin{tabular}{|c|c|c|}
\hline Designation & Denotation & Unit \\
\hline$p_{i, 3}, p_{i, 4}$ & Cylinder pressures, function i & $\mathrm{Pa}$ \\
\hline$p_{i, 5}, p_{i, 6}$ & Pressures at LHV inlets, function i & $\mathrm{Pa}$ \\
\hline$p_{i, 2}, p_{i, 2}$ & Pressures at valve outlets, function i & $\mathrm{Pa}$ \\
\hline$p_{\text {inlet }}$ & Pressure at valve inlet & $\mathrm{Pa}$ \\
\hline$p_{\text {pump }}$ & Pressure at pump outlet & $\mathrm{Pa}$ \\
\hline$p_{l s}$ & Load sensing pressure & $\mathrm{Pa}$ \\
\hline$p_{i, v}$ & $\begin{array}{l}\text { Pressure at active valve output, func- } \\
\text { tion } \mathrm{i}\end{array}$ & $\mathrm{Pa}$ \\
\hline$p_{i, l o s s}$ & Pressure defining LHV lowering losses & $\mathrm{Pa}$ \\
\hline$p_{i, b a c k}$ & Cylinder backside pressure, function i & $\mathrm{Pa}$ \\
\hline$p_{\text {tank }}$ & Pressure in tank & $\mathrm{Pa}$ \\
\hline$\Delta p_{\text {pump }}$ & Pump pressure margin & $\mathrm{Pa}$ \\
\hline$\Delta p_{\text {spool }}$ & Spool pressure drop & $\mathrm{Pa}$ \\
\hline$q_{\text {pump }}$ & Total flow from pump & $\mathrm{m}^{3} / \mathrm{s}$ \\
\hline$q_{i}$ & Flow to function $\mathrm{i}$ & $\mathrm{m}^{3} / \mathrm{s}$ \\
\hline$A_{\text {active }}$ & Area of active side of cylinder & $\mathrm{m}^{2}$ \\
\hline$A_{\text {back }}$ & Area of back side of cylinder & $\mathrm{m}^{2}$ \\
\hline$P_{\text {in }}$ & Electric power at battery & $\mathrm{W}$ \\
\hline$P_{\text {out }}$ & Hydraulic power at cylinder & $\mathrm{W}$ \\
\hline$P_{\text {loss }, \text { drive. }}$ & Power loss in drive system & $\mathrm{W}$ \\
\hline$P_{\text {loss, pumpline }}$ & Power loss in pumpline & $\mathrm{W}$ \\
\hline 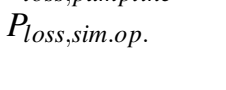 & $\begin{array}{l}\text { Power loss due to simultaneous opera- } \\
\text { tion of functions }\end{array}$ & $\mathrm{W}$ \\
\hline$P_{\text {loss }, p u m p \Delta p}$ & $\begin{array}{l}\text { Power loss due to constant pump pres- } \\
\text { sure margin }\end{array}$ & $\mathrm{W}$ \\
\hline$P_{\text {loss }, \text { spool } \Delta p}$ & $\begin{array}{l}\text { Power loss due to constant pressure } \\
\text { drop over spool }\end{array}$ & $\mathrm{W}$ \\
\hline$P_{\text {loss, hoses }}$ & $\begin{array}{l}\text { Power loss in hoses between main } \\
\text { valve and load holding valve }\end{array}$ & $\mathrm{W}$ \\
\hline$P_{l o s s, L H V, l i f t}$ & $\begin{array}{l}\text { Power loss in load holding valve during } \\
\text { lifting motions }\end{array}$ & $\mathrm{W}$ \\
\hline$P_{\text {loss }, L H V, \text { lower }}$ & $\begin{array}{l}\text { Power loss in load holding valve during } \\
\text { lowering motions }\end{array}$ & $\mathrm{W}$ \\
\hline$P_{\text {loss, backpressure }}$ & $\begin{array}{l}\text { Power loss due to backpressure in cyl- } \\
\text { inders }\end{array}$ & $\mathrm{W}$ \\
\hline$E_{\text {pump,red }}$ & $\begin{array}{l}\text { Energy consumption reduction for hy- } \\
\text { draulic system (energy taken from } \\
\text { pump) }\end{array}$ & - \\
\hline$E_{\text {bat }, \text { red }}$ & $\begin{array}{l}\text { Energy consumption reduction for } \\
\text { complete system (energy taken from } \\
\text { battery) }\end{array}$ & - \\
\hline
\end{tabular}

\section{References}

[1] Wolfgang Burget and Jürgen Weber. Mobile Systems - Markets , Industrial Needs and Technological Trends. In 8th International Fluid Power Conference (IFK), pages 23-54, Dresden, Germany, 2012.

[2] Björn Eriksson. Mobile Fluid Power Systems Design with a Focus on Energy Efficiency. PhD thesis, Linköping University, 2010.

[3] Mikael Axin. Fluid Power Systems for Mobile Applications with a Focus on Energy Efficiency and Dynamic Characteristics. Licenciate thesis, Linköping University, 2013.

[4] Karl-Erik Rydberg. Energy Efficient Hydraulics - System Solutions for Minimizing Losses Energy Efficient Hydraulics - System solutions for loss minimization. In National Conference on Fluid Power, Linköping, Sweden, 2015. 
[5] Jan Siebert, Marco Wydra, and Marcus Geimer. Efficiency Improved Load Sensing System - Reduction of System Inherent Pressure Losses. Energies, 10:941, 2017.

[6] Arnold Hießl and Rudolf Scheidl. Methodical loss reduction in load sensing systems based on measurements. In BATH/ASME 2016 Symposium on Fluid Power and Motion Control, Bath, UK, 2016.

[7] Milos Vukovic, Roland Leifeld, and Hubertus Murrenhoff. Reducing Fuel Consumption in Hydraulic Excavators - A Comprehensive Analysis. Energies, 10:687, 2017.

[8] Amy Rankka, Alessandro Dell'Amico, and Petter Krus. Drive Cycle Generation for a Hydraulic Loader Crane. In The 16th Scandinavian International Conference of Fluid Power, Tampere, Finland, 2019.

[9] U.S. Department of Energy. Adjustable Speed Drive Part-Load Efficiency, 2012.

[10] Abinab Niraula, Zhang Shuzhong, Tatiana Minav, and Matti Pietola. Effect of Zonal Hydraulics on Energy Consumption and Boom Structure of a Micro-Excavator. Energies, 11(8):2088, 2018.

[11] Johan Edén and Fabian Lagerstedt. An Electro-Hydraulically Controlled Cylinder on a Loader Crane. Master thesis, Linköping University, 2018.

[12] Mikael Axin, Björn Eriksson, and Jan-Ove Palmberg. Energy Efficient Load Adapting System without Load Sensing - Design and Evaluation. In The 11th Scandinavian International Conference on Fluid Power, Linköping, Sweden, 2009.

[13] Mikael Axin, Björn Eriksson, and Petter Krus. Flow versus pressure control of pumps in mobile hydraulic systems. Proceedings of the Institution of Mechanical Engineers. Part I: Journal of Systems and Control Engineering, 228(4):245-256, 2014.

[14] Bucher Hydraulics. Overall Efficiency Optimized, 2020.

[15] Christoph Latour. Elektrohydraulisches Flow-Matching (EFM) - Die nächste Generation von Load-SensingSteuerungen. Mobile 2006 - International Mobile Hydraulics Congress, Ulm, 2006.

[16] Martin Scherer, Marcus Geimer, and Björn Weiss. Forestry Crane with Electrohydraulic Flow-on-Demand System. In 71th Conference "LAND.TECHNIK - AgEng 2013", Hannover, 2013.

[17] Weiss Mobiltechnik GmbH. WMT part eBSS, 2019.

[18] Johan Nyman and Amy Rankka. Energy-efficient, Electro-Hydraulic Power Pack. Master thesis, Linköping University, 2015.

[19] M Djurovic and S Helduser. New Control Strategies for Electro-Hydraulic Load-Sensing. In Fluid Power and Motion Control (FPMC), pages 201-210, Bath, UK, 2004.

[20] Ruqi Ding, Bing Xu, Junhui Zhang, and Min Cheng. Bumpless mode switch of independent metering fluid power system for mobile machinery. Automation in Construction, 68:52-64, 2016.

[21] Eaton. Dynamic performance Empowering intelligent \& adaptable platforms, 2020.

[22] Samuel Kärnell. Fluid Power Pumps and the Electrification. Licenciate thesis, Linköping University, 2020. 